\title{
XXXII. Some account of a method which may be applied to the same purposes as Sir Isaac Newton's method of fluxions
}

\section{Mr. Thomas Tredgold}

To cite this article: Mr. Thomas Tredgold (1821) XXXII. Some account of a method which may be applied to the same purposes as Sir Isaac Newton's method of fluxions, Philosophical Magazine Series 1, 57:275, 200-202, DOI: 10.1080/14786442108652486

To link to this article: http://dx.doi.org/10.1080/14786442108652486

电 Published online: 27 Jul 2009.

Submit your article to this journal $₫$

Џll Article views: 2

Q View related articles $₫$ 
XXXII. Some Accoumt of a Method which may be applied to the sume Purposes as Sir IsaAC Newron's Method of Fluxions. By Mr. Thomas Tredgold.

\section{LETTER II.}

\section{To Mr. Tilloch.}

$\mathbf{S}_{\mathrm{IR}},-\mathrm{I}_{\mathrm{N}}$ my first letter (see p. 177 of this Number) on this subject, I explained a method of exhibiting the areas and the lengths of curves by means of progressions. I intend to show how the same principle may be applied to other parts of the method of fluxions ; but, before I proceed further, it will be neressary to show how such progressions may be summed: not that the problem has not been previously treated, but only because I follow a method of my own, which, perhaps, has advantages not common to other methods.

Assume a progression of the following form, and range the first differences of the adjoining terms below it: thus

$$
\begin{gathered}
0+a^{n}+(a+d)^{n}+(a+2 d)^{n}+\ldots(a+[m-1] d)^{n}+(a+m d)^{n} . \\
a^{n},(a+d)^{n}-a^{n},(a+2 d)^{n}-(a+d)^{n}, \ldots(a+m d)^{n}-(a+[m-1] d)^{n} .
\end{gathered}
$$

Then, it is easily proved that the last term of the progression is equal to the sum of all the differences. Also, if the second differences be taken, the last term of the first differences is equal to the sum of the second differences; and so of any other order of differences.

For example: If $n=1$, the differences will be $a, d, d, d, \&$ c. and if $S$ be taken to represent the sum of these differences, $\mathbf{S}=a+m d$.

Also, if $n=2$, then the differences will become

$$
\begin{gathered}
a, 2 a d+d^{2}, 2 a d+3 d^{2}, \ldots \ldots .2 a d+(2 m-1) d^{2} . \\
\text { and their sum } \mathrm{S}=(a+m d)^{2} .
\end{gathered}
$$

When $a=0$ the progression becomes extremely simple, and under this form I intend to show its application.

$$
\begin{aligned}
& \text { Prog. } 0+d^{n}+(2 d)^{n}+(3 d)^{n}+\ldots \ldots([m-1] d)^{n}+(m d)^{n} . \\
& \text { Diff. } d^{n},(2 d)^{n}-d^{n},(3 d)^{n}-\left(2 d^{n}, \ldots \ldots(m d)^{n}-\left([m-1 j d)^{n} .\right.\right.
\end{aligned}
$$

By means of this progression, any other which increases or decreases by the same law as the differences may be summed. This is effected by comparing the last term of the proposed one with the last difference of this progression: and if both be expressed by the same power or powers of $m$, with constant quantities; it only remains to determine the value of $d$, which is a 
constant quantity introduced in the above progression for the purpose of rendering it capable of being compared with progressions into which constant quantities enter.

As an example I shall take the progression

$$
\frac{a \cdot x^{n+1}}{2 m^{n+1}} \times\left(1+\left(1+2^{n}\right)+\left(2^{n}+3^{n}\right)+\ldots \ldots(m-1)^{n}+m^{n}\right)
$$

which, I have shown in my First Letter, will express the area of a curve of which the ordinate is $a x^{n}$ and the abscissa $x$.

The last term of this progression is $\frac{a x^{n+1}}{2 m^{n+1}} \times\left(\overline{m-1}^{n}+m^{n}\right)$.

And to make the last difference of the assumed progression contain the sane powers of $m$, when reduced, it must be

$(m d)^{n+1}-([m-1] d)^{n+1}=d^{n+1} \times\left(m^{n+1}-[m-1]^{n+1}\right)$.

Making

$\frac{a x^{n+1}}{2 m^{n+1}} \times\left([m-1]^{n}+m^{n}\right)=d^{n+1} \times\left(m^{n+1}-[m-1]^{n+1}\right)$, we find $d^{n+1}=\frac{a x^{n+1}}{2 m^{n+1}} \times\left(\frac{[m-1]^{n}+m^{n}}{m^{n+1}-[m-1]^{n+1}}\right)$. But the sum of the progression will be $(m d)^{n+1}=\frac{a x^{n+1}}{2} \times\left(\frac{m^{n}+[m-1]^{n}}{m^{n+1}-[m-1]^{n+1}}\right)$.

If the numerator and denominator of the latter part of this expression be expanded by means of the binomial theorem, we obtain the sum of the progression under the form

$$
\frac{a x^{n+1}}{n+1} \times\left\{\frac{1-n m^{-1}+n \frac{n-1}{2} m^{-2}-n \frac{n-1^{n}}{2} \frac{n-2}{3} m^{-3}+\& c .}{1-n n m^{-1}+n \frac{n-1}{3} m^{-2}-n \frac{n-1}{3} \cdot \frac{n-2}{4} m^{-3}+\& c .}\right\} \text {. }
$$

It will readily be seen that the sum of the progression can never be accurately represented by $\frac{a x^{n+1}}{n+1}$ except when $n=1$; but it is evidently nearer to the true sum in proportion as the value of $m$ is increased.

Let $\mathrm{AC}$ be a straight line, and make $\mathrm{AP}, a l, a^{\prime} b^{\prime}, a^{\prime \prime} b^{\prime \prime}, \& c$. each perpendicular to it; then, if $A \mathrm{~B}, a b, a^{\prime} b^{\prime}, \& \mathrm{c}$. represent the successive differences between $\frac{a x^{n+1}}{n+1}$ and the true sum of the progression corresponding to certain increased values of $m$, and if a line be drawn through the points $\mathrm{B}, b, b^{\prime}, 8 \mathrm{c}$. it will continually appronch the line $A C$, as a curve does to its asymptote;

Vol. 57. No. 275. March 1821 .

$\mathrm{C}$ c

but 
but so long as $m$ is any imaginable number these lines will not meet. It is therefore clear that we cannot express the area of

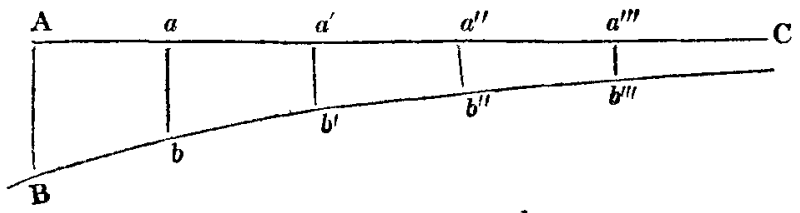

a curvilinear space accurately by $\frac{a x^{n+1}}{x+1}$ if it depends upon the sum of the progression being accurately given by the same expression. But it is obvious that in proportion as we increase the value of $m$, the progression approaches nearer to the true area of the space, because $\frac{x}{m}$ becomes less; and if we suppose this approach to accuracy to be measured by a deflexion of the line $\mathrm{AC}$ towards $\mathrm{B} l^{\prime \prime \prime}$, the two lines must ultimately meet. And as we can always suppose the value of $m$ to be such that they would meet; $\frac{a x^{n+1}}{n+1}$ must truly express the area.

The truth of the result is a consequence of the causes of error neutralising one another, and which necessarily flows from the method of investigation. The result is essentially the same as is obtained by the method of fluxions; indeed it is one of the most important of the rules of that celebrated method investigated by common processes. I much suspect that neither Sir Isaac Newton nor Leibnitz ever understood the real nature of the method of fluxions; if this suspicion be well founded (and the obscure or erroneous reasoning of its authors renders such a suspicion justifiable), there will be little difficulty in accounting for Sir Isaac's tardiness in publishing his discoveries. Under any other point of view his conduct appears inconsistent.

I shall most likely be accused of presumption in making the preceding remarks; but I would rather believe that the method of fluxions was the result of repeated trials, than that its author was indifferent about the progress of science, or that he wished to reserve to himself, as a miser does his gold, that which was a thousand times more valuable to his fellow men. I am, sir, yours \&e.

No. 2, Grove Terrace, March 14, 1821.

Thomas Tredgozd. 